\title{
EDITORIAL
}

\section{Render unto Caesar that which is Caesar's. Give credit to thy fellow author!}

I would like to share with the readers of this journal my experience and some thoughts concerning the apportionment of scientific credit or rather the lack of it, that is the omission of reference to the scientific work of others.

Time and again I hear frustrated authors complain to me that their paper(s) (published in Leukemia and perfectly relevant to a subsequent study published elsewhere) is/are not being cited. This problem is far from exclusive to papers published in Leukemia. Each of us is aware of the problem and many have encountered it. Either way, we must agree that loss of acknowledgement of relevant scientific results is akin to breach of moral copyight. I naturally share the frustration of the authors, particularly when thinkng of the intense teamwork linked to the publication of the article in question, as well as the anticipated pleasure to hearing echoes from the scientific community. More embarassing for me as the Editor is the other side of the coin, when Leukemia is the culprit and an article published in Leukemia omits citation of an article published in another journal. The summit of embarassment, though, is reached when an article published in Leukemia fails to cite relevant papers published previously in Leukemia itself.

One may question why it is so important to receive credit and if it is important, what can we do about the problem?

The crux of the matter is that to receive proper recognition for hard-won scientific results is not a matter of vanity. It is of paramount importance for a scientist's self-respect, his/her integration into the scientific 'community', and for establishing an essential network of connections with one's peers. In other words, it is important for professional fulfillment. Less important but still valid is the prejudice incurred by the Editor, whose work is judged each year on the Citation Index, and by the board members who lend their prestige and their support to a journal.

But there is a major financial aspect too, first and foremost for authors. The citation impact of each article together with the stature of the journal chosen for publication plays a major role in the evaluation of grant applications and for career progression. And what determines the stature of a journal if not the Citation Index of the journal? The same article published in a journal with a high citation index, will often have an added value for grant-givers, compared to the same article published in a journal with a lower citation index. Thus we touch upon a vital nerve in each other, when at times (and here I cannot give any statistics) we omit to cite each other. It may be that we have to reform the system of grants' evaluation but this is outside the scope of this Editorial!

Why does the omission occur? Sometimes because we judge the article to be a repeat of other articles. I am aware that one has to discuss when and when not to cite an article as it is not practicable to cite all articles. I have not defined the criteria with precision, but we all know intuitively that true first data are omitted in references. One may try to find realistic excuses. Sometimes the Editor has asked to delete references; (I try not to unless referees insist). Sometimes one is obliged to save on pages. Information provided by databases can be delayed and/or incomplete. On other occasions, however, I believe that we succumb to the temptation to reduce our search for extra references, tedious work even with the assistance of new computer software. I believe that failure to cite a paper is more likely an oversight and/or a negligence than a willful act, although we cannot exclude the latter and the victimized authors tend to favor this latter explanation.

Inadequate referencing may also indirectly have financial consequences for the publisher, in the form of lost prestige. One may say that this is none of our concern. But the fact is that governments who support scientists need results to be published, therefore scientific publishers are essential partners to national research programs worldwide. In turn, we Editors have a responsibility to protect their interests and take professional care of the product which they have launched with capital risk.

Therefore as discussed above, depriving a journal of citations is inflicting what in legal terms is called prejudice to 'intangible assets'. Though not part of this debate, I cannot resist stating that in return publishers owe us rapid publication time and good quality presentation particularly of figures, a demand which is not of an aesthetic nature but is mandatory for the article to be intelligible and therefore cited. Other than this, the success and usefulness of a journal depends much, albeit not entirely, on the hard work of the Editor, and of the board of the journal.

The Citation Index is not an absolute indicator of the value of a journal. Pursued to the extreme, it can distort the objective of publication itself, which is first and foremost to communicate reproducible data. Reliability of facts presented in an article is the major responsibility of a journal, and it can be reasonably achieved in an objective fashion, while the importance of an article is left to the more subjective evaluation of editors and 
referees. Thus there lies the danger of only 'hot', novel studies being accepted. I say danger because nobody can predict with certainty if a modest reliable study may not stir the imagination of another scientist, with more technical knowledge and powerful tools, and lead to a major break-through.

Obsession with the Citation Index can be at times very tiresome and can lead to an exaggerated rejection rate. In theory, an absurd situation could arise where a journal publishes just one article a year, which is cited many times and the Citation Index would eclipse all of its competitors. This notwithstanding, the struggle for citation rates is sharpening and the problems linked with the Citation Index have to be dealt with.

How can we ensure that we properly accredit each other? I believe in creating an atmosphere with more courtesy and sense of responsibility in openly discussing the problem.

I have no power over other journals except to recommend that authors raise the problem with the Editor and authors in question. I myself sometimes write to authors who should/could have cited a paper from Leukemia hoping that this may help in subsequent publications. If the opportunity arises I may tactfully question the author of a 'forgetful' article.

I have received various replies ranging from not reading Leukemia to the paper having slipped from the file. On occasion I have been more successful and the author received subsequent recognition, which confirms the fact that oversight is more frequent than willful acts. Authors should be encouraged to inform the Editor, if their paper published in Leukemia is not cited.

What am I to do when the negligence stems from papers accepted under my editorship and published in Leukemia itself? So far, when the complaint is official and formulated as a Letter to the Editor, I naturally publish it in the journal. If it is formulated over the telephone or in private, I check the record of this paper and make a mental note. I shall in the future incorporate a recommendation to referees to be particularly attentive to the problem of references. This is probably superfluous as I am amazed at the diligence of our referees but it will be done nevertheless. As an aside I salute all referees (the cornerstone of a good journal) and particularly those prepared to spend time on an unknown author, editor, or publisher to whom they owe nothing and from whom they receve nothing.

As far as Leukemia is concerned, I shall reinstate a practice whereby authors are encouraged at the time of submission to make an extra effort to check they have cited all papers relevant to their studies, including those in Leukemia. It complicates our administration but it is of benefit to all parties including the authors themselves, who may in the future enjoy the same attention, if their paper be published in Leukemia. It can be considered as a safeguard for authors publishing in Leukemia. In summary, my colleagues and I consider the correct citation of authors, who have entrusted us with their studies, is a matter of good publication practice and good etiquette.

This procedure should not be considered a gimmick to increase the citation index. A few added references will not influence the standing of Leukemia as this figure is dependent on citation from all the other journals in the field. It would not justify the extra work involved.

Generally speaking, two options could be considered to improve apportionment of scientific credit. It has been suggested that the name of the database(s) consulted be mentioned as a footnote in the article. Another possibility may be to create under Correspondence a rubric for authors who consider their paper has been overlooked. It should have a slightly different form from a Letter to the Editor, but the reasons for claiming credit clearly stated, the tone kept courteous, and the decision to publish at the discretion of the Editors and authors. This could lead to fruitful discussions. The point is that authors are in my experience often bashful about voicing their frustrations, therefore hesitant to do it in writing.

I welcome all suggestions and comment and I would like to encourage all Editors to be attentive to the problem raised in this editorial. Competition for funds is getting harder everywhere, scientists more and more harassed, therefore render unto Caesar that which is Caesar's. 